\title{
Trichobezoar-An Unusual Cause of Acute Appendicitis
}

\author{
Maj G J Attard \\ MD, FRCS, RAMC \\ British Military Hospital, Rinteln
}

SUMMARY: Various exotic foreign bodies have been found in the lumen of acutely inflamed appendices. $\stackrel{\infty}{~}$ The list includes parasites, pips, chips of bone, metal and wood. In the following case the cause of $\vec{\circ}$ obstruction was a trichobezoar.

\section{Case Report}

The patient, a previously perfectly healthy nine year old boy, was admitted to hospital in the early hours of the morning. He gave a history very suggestive of acute obstructive appendicitis. He complained of colicky mid-abdominal pain starting 24 hours prior to admission. On admission the pain was in the RIF (right iliac fossa). He also felt nausealed and had vomited repeatedly for several hours.

On examination he had foetor oris as well as tenderness and some guarding in the RIF. His temperature was $37.7^{\circ} \mathrm{F}$. His white cell count was 12.000 per cu $\mathrm{mm}\left(10 \times 10^{9}\right)$ with an elevated polymorph count.

At laparotomy an inflamed retrocaecal appendix was present and removed. On splitting the appendix in theatre it was found to contain an occluding mass of hair that closely matched the patients own (Fig. 1). The unusual findings brought a smile to the face of a disgruntled anaesthetist and a dry comment that the patient showed signs of a recent hair cut.

The patient made an uneventful recovery. He later admitted that following a recent visit to the barber he had spent the afternoon playing "Jaws" in the bath. The quarry in this case were bits of his newly cut hair that had washed off into the water.

\section{Discussion}

A Bezoar is a mass of insoluble animal, vegetable or mineral material in the intestinal canal. It is derived from a Persian word, which means 'against poison' because some orientals recovered hair balls from the stomach of animals and used them as an antidote against poison.
A Trichobezoar (hair ball) is a rare condition usually encountered on the shelves of pathological museums. Standard textbooks describe them as occurring in nervous youngsters or insane persons and almost exclusively in women. Most are found ${ }^{\circ}$ in the stomach where they may form a cast the entire stomach, including the duodenal cap. Theog o then can give rise to gastroduodenal ulceration perforation, peritonitis or obstruction.

In conclusion the unusual combination of a rard cause of a very common condition and a smilin $\frac{7}{\mathrm{~s}}$ anaesthetist in the early hours of the morning described.

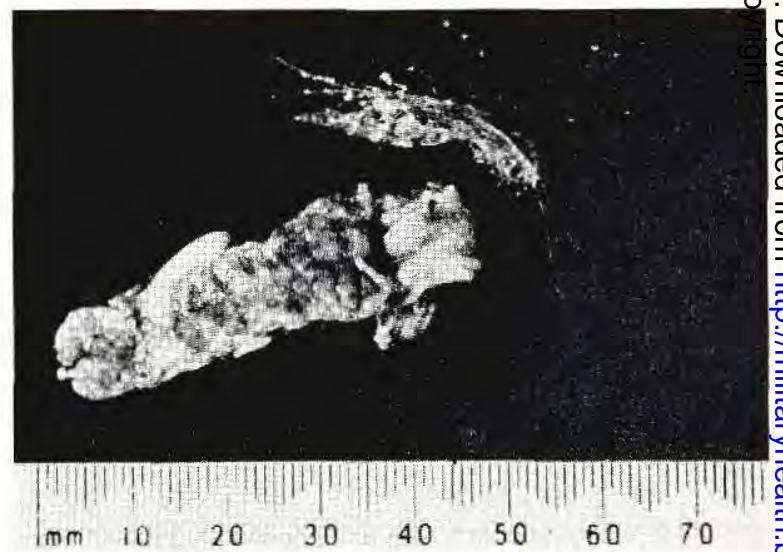

Fig. I Showing occluding mass of hair found in the appendix

REFERENCF

1 BAILEY AND Loves Short Practice of Surgery 18th ed. H K Lewis \& Co Ltd., 1981. 